\title{
MAGNETIC SEPARATION OF CALCITE USING SELECTIVE MAGNETITE COATING
}

\author{
S. PRAKASH ${ }^{\mathrm{a}, *}$, B. DAS $^{\mathrm{a}}$ and R. VENUGOPAL ${ }^{\mathrm{b}}$ \\ ${ }^{a}$ Regional Research Laboratory (CSIR), Bhubaneswar, 751013, India; \\ ${ }^{\mathrm{b}}$ Indian School of Mines, Dhanbad, 826004, India
}

(Received 30 September 1998; Accepted 22 December 1998)

\begin{abstract}
Magnetic separation of naturally occurring calcite $\left(98.2 \% \mathrm{CaCO}_{3}\right)$ using selective coating of synthetic colloidal magnetite with sodium oleate has been investigated as a function of $\mathrm{pH}$, concentration of colloidal magnetite, magnetic intensity and particle size. Colloidal magnetite treated with sodium oleate (oleate magnetite) is found to be a better coating agent than the natural magnetite. The mechanism of oleate magnetite coating has been investigated through adsorption and electrokinetics measurements. FTIR studies indicate that there is a possible chemical interaction between calcite and magnetite surfaces on which sodium oleate is adsorbed. Magnetic susceptibility measurement shows a finite susceptibility of calcite by the addition of colloidal magnetite. In the investigation with calcite, calcite recoveries of $>94 \%$ have been achieved at a colloidal magnetite concentration of $0.25 \mathrm{ml} / \mathrm{g}$ and $7.1 \mathrm{kG}$ of magnetic intensity. In case of synthetic mixture of calcite and quartz $>90 \%$ calcite recovery at a grade of $80.9 \% \mathrm{CaCO}_{3}$ has been achieved at the optimum $\mathrm{pH}$ of 11 .
\end{abstract}

Keywords: Magnetite; Coating; Magnetic separation; Sodium oleate; Calcite

\section{INDRODUCTION}

The processing of a calcite ore frequently leads to the generation of ultrafine particles that are very difficult to treat by conventional mineral processing techniques. These low grade fines represent one of the main losses of values in the mining sector of India. It is well known that selective particle coating is a promising method which has shown the potential of separating minerals by magnetic separation technique [1]. The magnetic response of a specific mineral is largely dependent on its magnetic susceptibility. The response of a weakly magnetic or

\footnotetext{
* Corresponding author.
} 
non-magnetic substance can be increased considerably by incorporating a strongly magnetic phase such as natural magnetite or colloidal magnetite into the surface of the material. The formation of selective particle coating leads to the separation of minerals and have shown the potential of treating variety of mixtures by magnetic separation techniques.

It has been shown by Sauck [2] that, only $0.01-0.1 \%$ by volume of magnetite per particle is needed to increase the magnetic susceptibility of the non-magnetic minerals to a considerable extent. The fine particle separation by selective magnetic coating has recently received some attention. Separation of many weakly magnetic minerals such as chalcocite from silica, sphalerite from silica and fine coal from ash using magnetic coating has been described by Shubert [3]. Selective coating of calcite and dolomite using magnetite was carried out by Parsonage et al. [4]. Other methods using magnetic coating have also been described by Taggart, De Latour and Iwasaki, for different minerals [5-7]. The coating of magnetite on titanium and iron bearing impurities has been described by Cook and Nott and Price [8,9]. The role of magnetite and sodium oleate in HGMS separation of calcite using magnetite coating has been described by Ahamad et al. [10]. The principles of surface chemical parameters that govern selective adsorption of magnetite have been discussed by Parsonage [1] and Qingxia Liv and Friedlaender [11]. Factors that influence the addition of magnetite include electrical charge of minerals, magnetite, presence of adsorbed surfactant on the mineral surface and electrolytic concentration of the pulp.

In the present investigation, the coating of calcite by the oleate colloidal magnetite has been carried out to study the separation efficiency of a synthetic mixture of calcite and quartz using a wet magnetic separator. The effect of different parameters, namely $\mathrm{pH}$, magnetic intensity, magnetite concentration etc. has been studied. FTIR, zeta potential measurement and the chemistry governing the coating mechanism have been carried out and discussed in this paper.

\section{EXPERIMENTAL}

\section{Materials}

The minerals and reagents used in the present investigation are as follows. 
(a) Calcite Selected white transparent crystals of calcite obtained from one of the mines under the lease hold of Orissa Mining Corporation India, were used in the present work. The sample was ground in a pulveriser, washed several times with distilled water to remove any contaminated colloidal particles and then dried. The sample was sieved to different sizes viz, $-150+75,-75+30$ and $-30 \mu \mathrm{m}$ for the experimental work.

(b) Quartz Well crystallised samples of pure quartz from Kanchekera, Karnataka, India assaying around $99.96 \% \mathrm{SiO}_{2}$ were used. The sample was prepared by grinding in a stainless steel ball mill. The ground material was washed several times with dilute hydrochloric acid followed by distilled water to remove any contaminated iron and the finely divided particles. The sample was classified into sizes similar to calcite.

(c) Colloidal and Oleate Magnetite The colloidal magnetite was prepared similarly to the method reported by Parsonage [1]. It was prepared by a combination of ferrous and ferric salts in $1: 1$ ratio. The oleate magnetite was prepared at $\mathrm{pH} 11$ by boiling it until the colloidal are completely dispersed.

(d) Magnetite Natural magnetite was obtained from the Kudremukh Iron Ore Company Ltd., India. Its total Fe content was $69.9 \%$. The size of the sample used in the investigation was less than $5 \mu \mathrm{m}$. The fine sample was obtained by grinding for four hours in a manganese steel mill followed by careful sieving. This magnetite was also used as a coating substance for calcite.

\section{METHODS}

\section{Magnetic Separation}

Magnetic separation studies were carried out by a wet high intensity magnetic separator type A1/4253, serial No. J 51930, LHW supplied by Rapid Box-Mag separator, England, at different magnetic intensity. Magnetic intensity can be varied with current and separating grids. The grids are magnetic stainless steel wedged wire which are spaced to form an element. Several elements are spaced apart to form a grid. The grid is inserted into the holder which is positioned between the magnetic poles. Grids of $1.0 \mathrm{~mm}$ spacing between the wire were used for $-150+75$ 
and $-75+30 \mu \mathrm{m}$ sized materials and stainless wire wool were used for $-30 \mu \mathrm{m}$ sized fractions.

The slurry was then passed slowly through the wet magnetic separator. The magnetic fraction was retained on the grid whereas the nonmagnetic fraction was collected at the bottom. The magnetic fraction was recovered from the separating grids by washing with water in the absence of the magnetic field. The magnetic and non-magnetic fractions thus collected separately were dried and analysed to check the purity and the recovery of the products.

\section{Magnetic Susceptibility Measurements}

Magnetic susceptibility of the pure calcite and of calcite treated with different amounts of oleate magnetite was measured in a low field susceptibility hysteresis apparatus, based on a balanced double coil system. A specimen kept at the centre of a balanced double coil which itself is at the centre of a Helmholtz coil system producing an alternating magnetic field, behaves like an alternating dipole and induces a differential emf in the double coil. Power to the Helmholtz coil is supplied by an oscillator and a high quality amplifier. The signal induced in the double-coil, which is proportional to the rate of the change of the magnetic movement of the specimen is amplified using a phase lock arrangement and displayed on a digital voltmeter. The meter reading can be calibrated in terms of magnetic moment. Knowing the magnetic field and the volume or the weight of the specimen, its susceptibility can be calculated.

\section{Electrokinetic Measurements}

The electrokinetics mobility of minerals was determined using Rank Brothers model Mark II. The experiments were conducted in a thin walled flat cell using two platinum wires as the electrodes. The value was converted to zeta potential by means of the Smoluchowski equation. $\mathrm{NaNO}_{3}$ was used as the supporting electrolyte and the ionic strength of the suspension was maintained at a concentration of $2 \times 10^{-3} \mathrm{M}$ in all the experiments. A finely ground sample below $5 \mu \mathrm{m}$ was used. The measurements of zeta potential was done with the colloidal and oleate magnetite in a very dilute suspension $(1 \mathrm{ml}$ of suspension in $200 \mathrm{ml}$ of 
distilled water). The conditioning of the suspension was carried out for two hours prior to the measurement to assess the stability of the suspension. The $\mathrm{pH}$ of the solution was regulated either by addition of dilute acid or alkali.

\section{The Coating Studies}

This study is almost similar to the adsorption studies. Instead of a solute from a solution, colloidal particles are used to coat the solid surfaces to impart magnetic properties to the surface. Five grams of accurately weighed calcite were taken in a series of $100 \mathrm{ml}$ of conical flask fitted with a stopper. Different amounts of oleate magnetite suspension were placed in these flasks. The flasks were shaken at room temperature with the help of Julubo metabolic electric shaker. The shaker is provided with variation of temperature and speed of shaking. The $\mathrm{pH}$ of the suspension was adjusted previously either with dilute perchloric acid or by sodium hydroxide. After the specified period of time suspensions were sieved at $30 \mu \mathrm{m}$ ISS sieves and the supernatants were carefully taken out.

The initial and the final concentrations of the colloidal magnetite suspensions were determined gravimetrically after carefully drying and weighing both the residue and supernatants in a well calibrated electronic balance. The amount of colloidal magnetite coated was calculated from the difference of concentrations. The weight of the residue left on the sieve was taken after thorough washing with distilled water. The period required for attaining equilibrium was determined after carrying out several adsorption tests for different intervals of time. The time requirement for attaining a constant value of concentration of colloidal magnetite in the supernatant was determined by the number of tests. The coating by oleate magnetite on the calcite surface was also studied at different temperatures by Julabo mechanical shaker and the measurement of concentration of oleate magnetite was done after allowing sufficient time to attain equilibrium. The low temperature adsorption experiments were carried out after adding ice into the water bath of the shaker.

\section{FTIR Studies}

The FTIR spectra were recorded by using JASCO Fourier Transform infrared spectrophotometer model 5300 over KBR disc pellets. The disc 
was prepared by mixing approximately $200 \mathrm{mg}$ of KBR and $0.2 \mathrm{mg}$ of the sample. The mixture was mixed thoroughly and then transferred to the die. The die was first evacuated for $5 \mathrm{~min}$ followed by a pressure of five tonnes. The pressed sample in the form of a disc was then subjected to FTIR experiments.

\section{RESULTS AND DISCUSSION}

\section{Magnetic Separation Studies}

Calcite is essentially non-magnetic in nature. Some blank runs were carried out at different magnetic intensities at constant $\mathrm{pH}$ of 10.7 without adding any oleate magnetite or colloidal magnetite. The results are shown in Table I. It can be seen that calcite behaves like nonmagnetic in the absence of the magnetite material. Only $4.5 \%$ of calcite was reported in magnetic fraction at an intensity of $10 \mathrm{kG}$.

\section{The Effect of $\mathbf{p H}$}

The results plotted in Fig. 1 show that $\mathrm{pH}$ of the suspension plays a major role in the recovery of calcite. The effect of $\mathrm{pH}$ at various magnetic intensities indicates that the recovery increases with the increases in the $\mathrm{pH}$ values. The recovery of $94 \%$ at $\mathrm{pH} 11.0$ at a magnetic intensity of $7.1 \mathrm{kG}$ was achieved. At other $\mathrm{pH}$ values, the recovery ranged from $51 \%$ to $74 \%$. It is shown that the maximum coating of oleate magnetite has taken place at $\mathrm{pH} 11.0$. The recovery of calcite increases linearly with the increase in the magnetic intensity. The experiments were carried out on the size fraction $-150+75 \mu \mathrm{m}$ at a constant oleate magnetite dosage of $0.25 \mathrm{ml} / \mathrm{g}$ of calcite.

TABLE I Blank wet magnetic separation of calcite

\begin{tabular}{lc}
\hline $\begin{array}{l}\text { Magnetic intensity } \\
(\mathrm{kG})\end{array}$ & $\begin{array}{c}\text { Calcite } \%, \text { magnetic } \\
\text { fraction }\end{array}$ \\
\hline 3.0 & 0 \\
5.0 & 0 \\
6.5 & 0 \\
7.1 & 1.2 \\
5.5 & 2.2 \\
6.5 & 4.5 \\
\hline
\end{tabular}




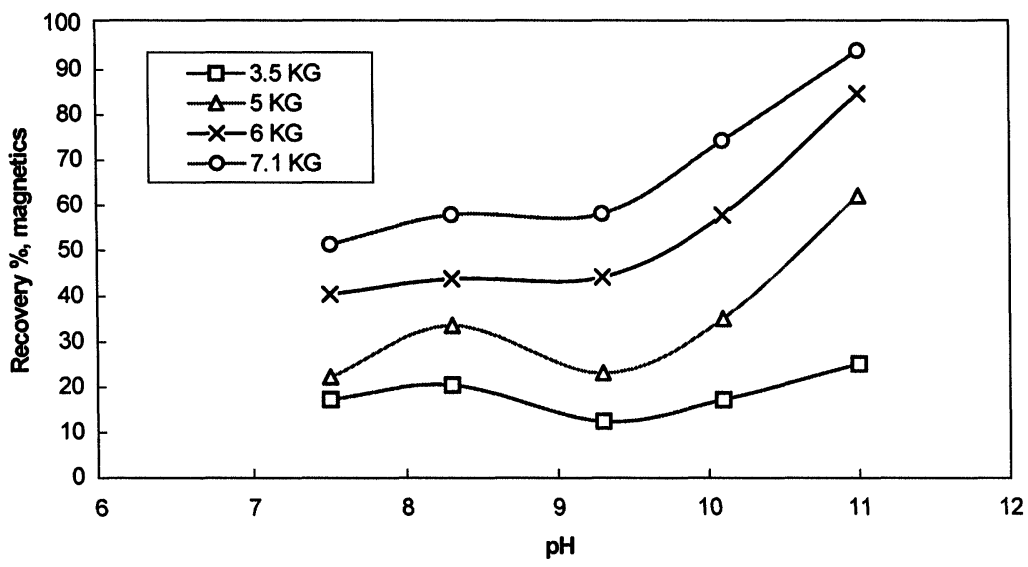

FIGURE 1 The effect of $\mathrm{pH}$ on the recovery of calcite at different magnetic intensities (oleate magnetic colloidal $0.25 \mathrm{ml} / \mathrm{g}$ ).

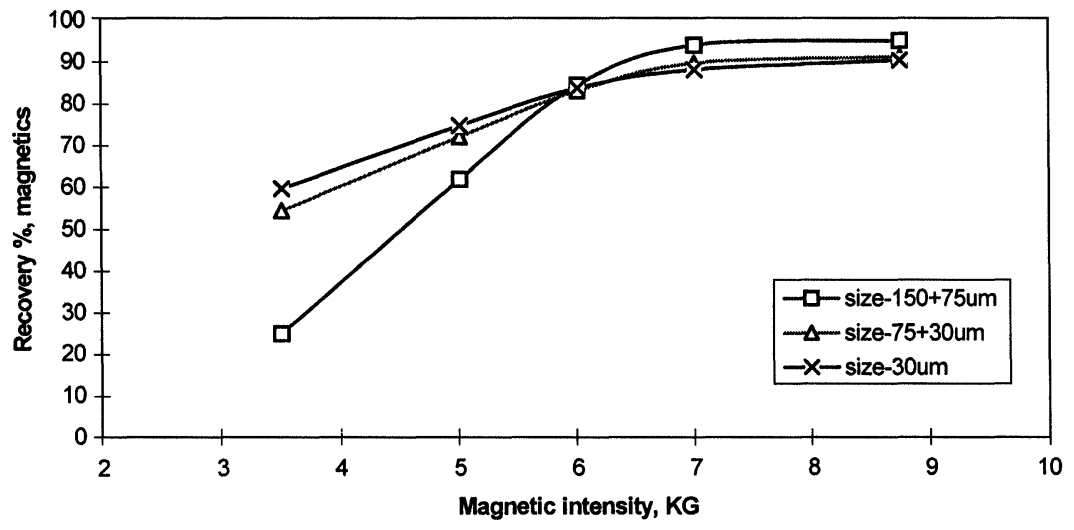

FIGURE 2 The effect of particle size on the recovery of calcite at different magnetic intensities (oleate magnetic colloidal: $0.25 \mathrm{ml} / \mathrm{g}, \mathrm{pH}: 11$ ).

\section{The Effect of Particle Size}

The results of magnetic separation studies at three different size fractions viz. $-150+75,-75+30$ and $-30 \mu \mathrm{m}$ at $\mathrm{pH} 11.0$ and different magnetic intensities were studied and are shown in Fig. 2. It can be seen that with the increase in the particle size the recovery of calcite increases progressively from $88 \%$ to $94 \%$ at the intensity of $7.1 \mathrm{kG}$ in all 
the three sizes. This may be due to the difference in the specific surface area of the particles. The influence of the size has some predominant effect at lower magnetic field strengths.

\section{The Effect of the Oleate Magnetite Concentration}

Some experiments were undertaken at $\mathrm{pH} 11.0$ to examine the effect of the oleate magnetite addition on the recovery of calcite. Three levels of magnetic intensity i.e. at $3.5,5$, and $7.1 \mathrm{kG}$ were set during experiments. The results of the magnetic separation tests at different oleate magnetic concentrations with different magnetic intensities are shown in Fig. 3. It can be seen that the recovery of magnetics increases progressively, and even at $3.5 \mathrm{kG} 71 \%$ calcite is being recovered. It is also seen from Fig. 3 that the increase in the oleate magnetite concentration increases the recovery of calcite with intensity of magnetic field. At a higher concentration of oleate magnetite, 5 to $6 \mathrm{kG}$ of magnetic intensity is sufficient to get the best results. However the oleate magnetite dosage of $0.25 \mathrm{ml} / \mathrm{g}$ of calcite at a magnetic intensity of $7.1 \mathrm{kG}$ is sufficient to lift the calcite particles.

\section{The Effect of Magnetic Field Intensity}

It has been estimated that $0.25 \mathrm{ml} / \mathrm{g}$ of oleate magnetite per gram of calcite is necessary to form coating on calcite surface at $\mathrm{pH} 11.0$. A few

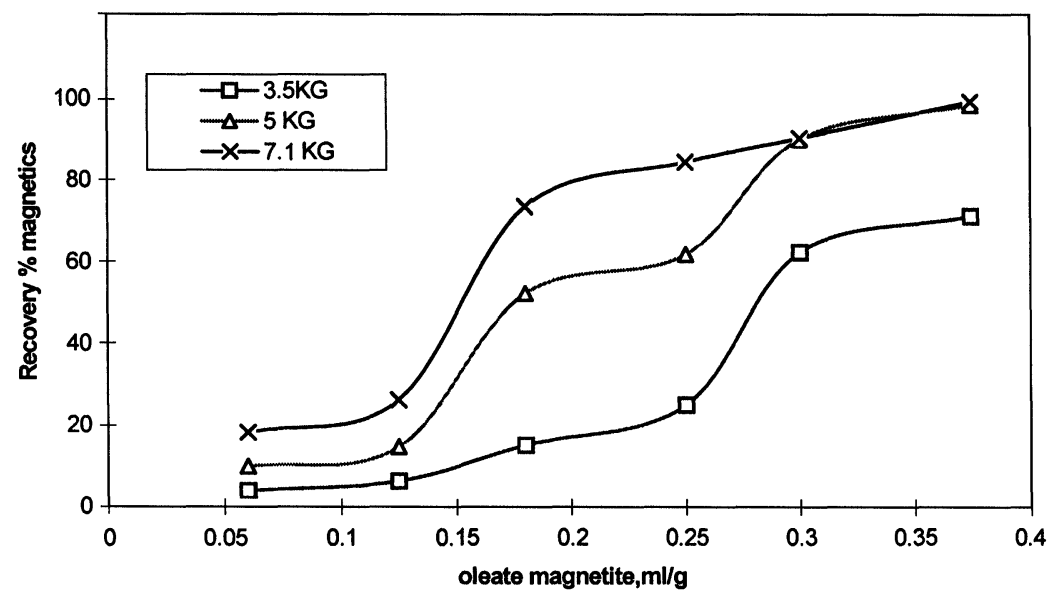

FIGURE 3 The effect of the oleate magnetite concentration on the recovery of calcite at different magnetic intensities (size $-150+75 \mu \mathrm{m}$ ). 


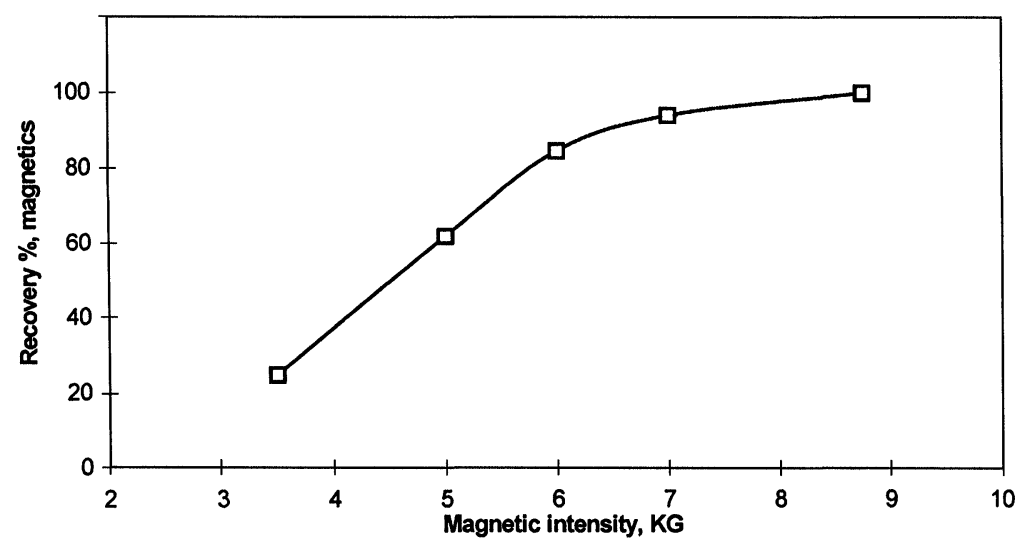

FIGURE 4 The effect of the magnetic intensity on calcite recovery (oleate magnetite: $0.25 \mathrm{ml} / \mathrm{g}$, size $-150+75 \mu \mathrm{m})$.

more experiments were conducted to understand the effect of the magnetic field intensity on the recovery of calcite. By changing the magnetic field from 3.5 to $9 \mathrm{kG}$ at $\mathrm{pH} 11.0$ the recovery increases from $23.2 \%$ to $99 \%$ (Fig. 4). However as is seen in the experiments, the particle size, $\mathrm{pH}$ and conditioning time play an important role in the selective separation process.

\section{Separation of Calcite with Natural Magnetite}

The effectiveness of selective magnetic coating on calcite was attempted by using ground natural magnetite. The separation of coated calcite was carried out at $\mathrm{pH} 11$. The results of magnetic separation at various dosages of natural magnetite and sodium oleate are shown in Table II. In the absence of oleate and with $17.7 \mathrm{mg}$ of magnetite only $27.2 \%$ of calcite could be recovered. The recovery increased with the addition of small amount of oleate. The recovery increased to $97.5 \%$ at magnetite concentration of $100 \mathrm{mg} / \mathrm{g}$ of calcite. Further experiment carried out with $73.3 \mathrm{mg}$ of magnetite with different dosage of oleate suggests that $100 \%$ of calcite recovery can be obtained at $10 \mathrm{mg} / \mathrm{g}$ sodium oleate. This establishes that ground mineral magnetite along with sodium oleate can also be used as the coating agent in the system. However, since the quantity of natural magnetite used is somewhat high, additional process step has to be incorporated to recover the 
TABLE II Results of magnetic separation on calcite using natural magnetite and sodium oleate (magnetite $-5 \mu \mathrm{m} \mathrm{pH} 11$, calcite $-150+75 \mu \mathrm{m}$, magnetic intensity $9.0 \mathrm{kG}$ )

\begin{tabular}{lcc}
\hline Magnetite, $\mathrm{mg} / \mathrm{g}$ & Sodium oleate, $\mathrm{mg} / \mathrm{g}$ & Recovery $\%$ \\
\hline 17.7 & - & 27.2 \\
17.7 & 5.33 & 48.1 \\
33.3 & 5.33 & 60.4 \\
50.0 & 5.33 & 76.0 \\
73.3 & 5.33 & 85.0 \\
100.0 & 5.33 & 97.5 \\
73.3 & 6.66 & 95.2 \\
73.3 & 8.66 & 96.7 \\
73.3 & 10.0 & 100.0 \\
\hline
\end{tabular}

TABLE III Results of magnetic separation of calcite quartz mixture $(1: 1)$ using oleate magnetite (size $-150+75 \mu \mathrm{m}$, oleate magnetite $0.25 \mathrm{ml} / \mathrm{g}$ )

\begin{tabular}{lcccccccc}
\hline Details & \multirow{2}{*}{ kG } & Weight $\%$ & \multicolumn{2}{c}{ Grade \% } & & \multicolumn{2}{c}{ Recovery \%, $\mathrm{pH} 11$} & \multirow{2}{*}{$\begin{array}{c}\text { Recovery \%, } \\
\text { Calcite, } \mathrm{pH} 8.5\end{array}$} \\
& & & Calcite & Quartz & & Calcite & Quartz & \\
\hline Mag. I & 3.5 & 27.8 & 80.0 & 20.0 & & 45.8 & 10.7 & - \\
Mag. II & 5.0 & 54.6 & 80.9 & 19.6 & & 90.9 & 20.7 & 27.9 \\
Mag. III & 6.0 & 59.3 & 77.8 & 22.7 & & 95.0 & 26.0 & 57.0 \\
Non-Mag & - & 40.7 & 6.0 & 94.0 & & 5.0 & 74.0 & 43.0 \\
Head & - & 100.0 & 48.5 & 51.5 & & 100.0 & 100.0 & 100.0 \\
\hline
\end{tabular}

magnetite as suggested in the selective flocculation of hematite from silica [7].

\section{Separation of Calcite-Quartz Mixture}

The removal of quartz is important in the upgrading of fine calcite. The recovery of calcite and quartz from a mixture $(1: 1)$ to the magnetite fraction after treatment with oleate magnetite at $\mathrm{pH} 11$ and 8.5 is shown in Table III. The effect of $\mathrm{pH}$ on the recovery of calcite indicates that $\mathrm{pH}$ of 11 gives the highest separation of calcite. The amount of oleate magnetite required to produce a magnetic coating on the calcite and the magnetic intensity required for the separation is same as that for the pure calcite studied earlier. The improved separation is due to the increased magnetic susceptibility of calcite by the addition of oleate magnetite. The present study has indicated that $91 \%$ recovery of calcite at the grade of $80.9 \% \mathrm{CaCO}_{3}$ can be achieved at the magnetic intensity 


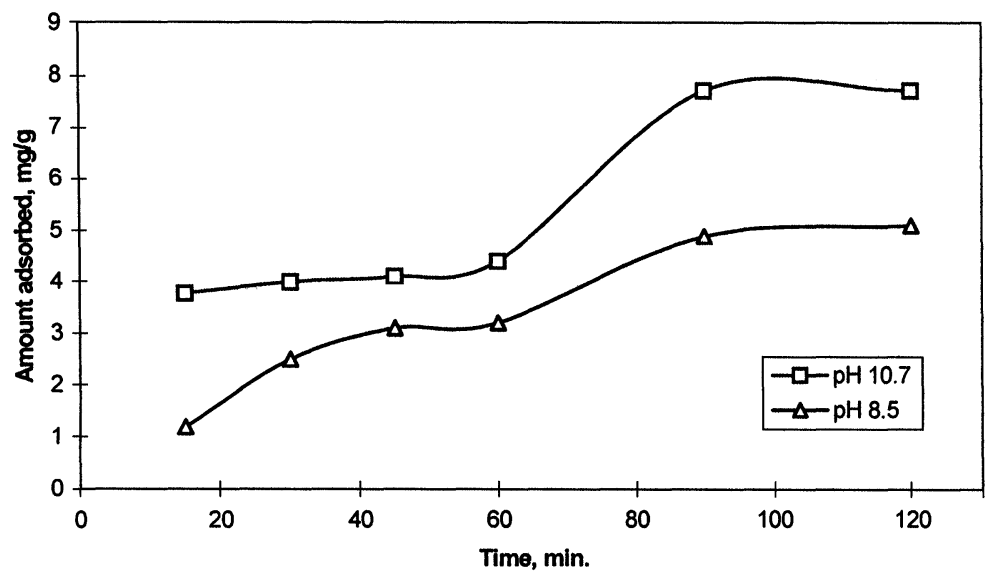

FIGURE 5 The coating of oleate magnetite on calcite as a function of time $(0.25 \mathrm{ml} / \mathrm{g}$ of oleate magnetite).

of $5 \mathrm{kG}$. It is also seen that further increase in the magnetic intensity to $6.0 \mathrm{kG}$ decreases the grade of calcite.

\section{The Coating Studies}

The amount of oleate colloidal magnetite coated as a function of time at a constant colloidal concentration at $\mathrm{pH} 8.5$ and 10.7 is shown in Fig. 5. It can be seen that the oleate magnetite coating on calcite takes place very slowly during the first $60 \mathrm{~min}$ and then it progresses fast. Since it was found that the equilibrium was not attained even after $100 \mathrm{~min}$, about $150 \mathrm{~min}$ were provided to attain equilibrium. The coating was found to be better at $\mathrm{pH}$ 10.7. Further experiments were thus carried out at that $\mathrm{pH}$ only.

The coating of colloidal magnetite at different $\mathrm{pH}$ values is given in Fig. 6. The amount coated increases with the increase in $\mathrm{pH}$ but decreases for $\mathrm{pH}$ greater than 10.7. The electrokinetics study also indicates that the minimum zeta potential of the calcite sample is around pH 10.7 (Fig. 12) where the maximum coating occurs. The coating of oleate magnetite on calcite similar to adsorption isotherms is shown in Fig. 7. It is obtained by plotting the equilibrium amount of reagent coated $(\mathrm{mg} / \mathrm{g})$ versus equilibrium concentration $(\mathrm{mg} / \mathrm{l})$ of the corresponding colloidal solutions. The $\mathrm{pH}$ of the solution containing the 


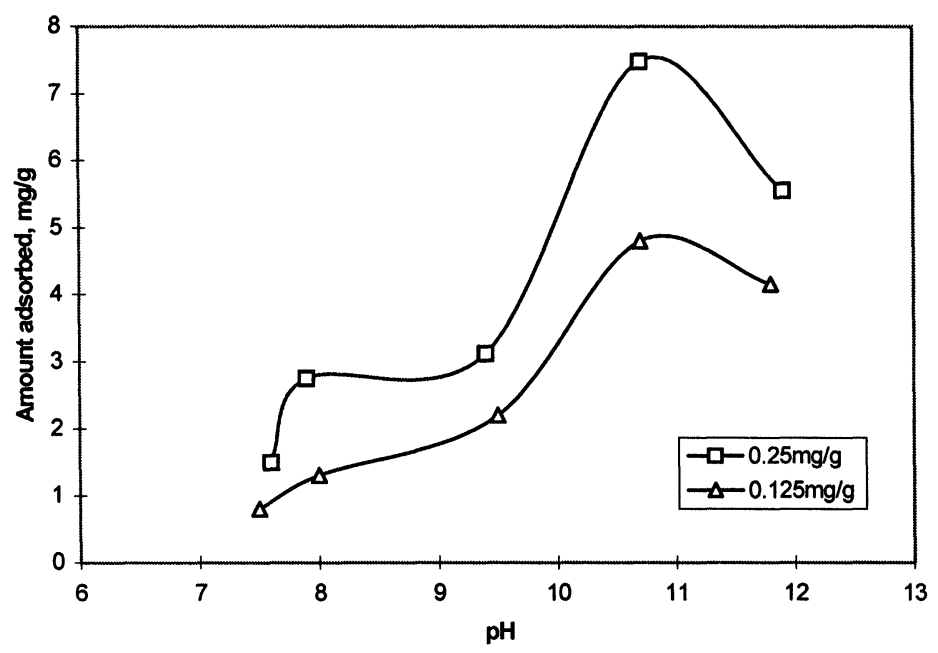

FIGURE 6 The coating oleate magnetic colloidal on calcite at different $\mathrm{pH}$.

oleate magnetite has not changed appreciably due to change in concentration within which the studies have undertaken. The isotherm follows a linear increase of the amount adsorbed. The isotherm presented in Fig. 7 shows resemblance to L type curves as classified by Giles et al. [12]. At higher equilibrium concentration i.e. $115.4 \mathrm{mg} / 1$, the coating increases almost asymptotically.

The plot of $\log$ (equil. conc. $\mathrm{mg} / \mathrm{l}$ ) versus $\log$ amount coated follows more or less Freundlich relation as is evident from Fig. 8. The slope of the straight lines thus obtained is 1.23 . In the present work the coated material contains an unsaturated carboxylic group which is responsible for adsorption into the calcium ions. This carboxylate group is attached to the substrate first. The adsorbed oleate molecule further hold other molecule which is bound to magnetite and the co-operative adsorption takes place. After attaining a plateau region the coating sharply increases representing multilayer adsorption. The slope value greater than 0.5 indicates that the coating/adsorption in the present system is mostly governed by chemisorption.

The coating of oleate magnetite on calcite at different temperatures is shown in Fig. 9. It can be seen that when the temperature raises from $18^{\circ} \mathrm{C}$ to $26^{\circ} \mathrm{C}$ the coating initially increases but decreases further with 




FIGURE 7 The coating of oleate magnetite on calcite as a function of equlibrium concentration.

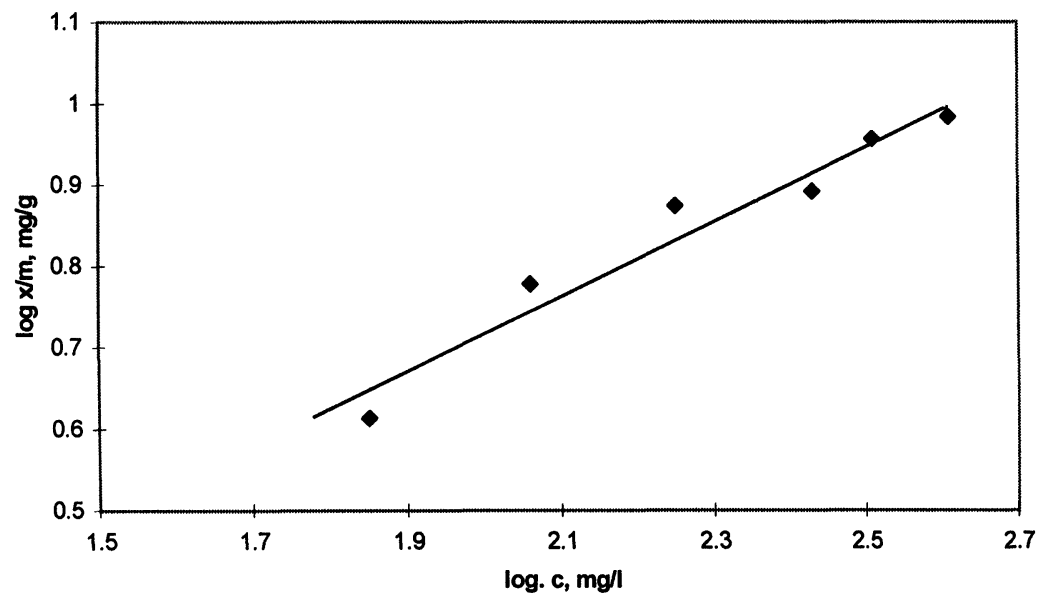

FIGURE 8 Freundlich plot of $\log c$ vs $\log x / m$ for the adsorption of oleate magnetite on calcite.

the increase of the oleate magnetite concentration. In the case of other temperatures $\left(40^{\circ} \mathrm{C}, 60^{\circ} \mathrm{C}\right)$ the coating increases with the increase in the oleate magnetic concentration. This indicates that at a higher temperature both physical and chemical adsorption of oleate magnetite is taking place. 




FIGURE 9 The coating of oleate magnetite on calcite at different temperatures (pH 10.7).

\section{FTIR Spectroscopy}

The FTIR spectra were recorded in the range of $400-4000 \mathrm{~cm}^{-1}$ on a Fourier transform infrared spectrometer over a KBR disc. The spectra of magnetite and oleate magnetite that interacted with calcite were investigated to find a possible interaction between calcite and colloidal magnetite on which oleate is adsorbed.

The FTIR spectra of the colloidal magnetite, oleate magnetite and calcite treated with oleate magnetite are shown in Fig. 10. Three adsorption bands were observed at 1107,893 and $565 \mathrm{~cm}^{-1}$ with respect to the colloidal magnetite similar to the characteristic peaks of natural magnetite [13]. The peaks appearing at 1557 and $1525 \mathrm{~cm}^{-1}$ due to $-\mathrm{C}=\mathrm{C}$ and $\mathrm{CH}_{2}-\mathrm{CH}_{2}-\mathrm{C}-\mathrm{C}$ of oleate magnetite confirm the formation of oleate magnetite [14]. Another peak appearing at $2919 \mathrm{~cm}^{-1}$ in the compound is due to the asymmetric stretching vibration of $\mathrm{CH}_{2}$ group. It is also well known from analytical chemistry that a reaction of sodium oleate with ferric ion leads to the formation of ferric oleate. The infrared spectra (Fig. 10 (III)) of calcite interacting with oleate magnetite show a peak around $1100 \mathrm{~cm}^{-1}$. It is due to the formation of $-\mathrm{C}-$ $\mathrm{O}-\mathrm{C}$ crosslinking between the hydrocarbon chains [15]. The crosslinking may result in polymerisation of the hydrocarbon chains of oleate 




FIGURE 10 FTIR Spectra of (I) Colloidal magnetite (II) Oleate magnetite and (III) Calcite coated with oleate magnetite.

as suggested by Ahamad et al. [10]. The other peaks around 876, $1610 \mathrm{~cm}^{-1}$ due to magnetite are shifted considerably.

Peaks appearing at $1505 \mathrm{~cm}^{-1}$ due to $\mathrm{CH}_{2}-\mathrm{CH}_{2}-\mathrm{C}-\mathrm{C}$ formation of ferric oleate are also shifted due to the interaction of calcite. Moreover, the formation of the calcium oleate complex on the surface has already 
been established [16]. It can thus be concluded that there is a strong interaction between calcite and oleate magnetite leading to the $-\mathrm{C}-\mathrm{O}-$ $\mathrm{C}$ crosslinking.

\section{Electrokinetics Studies}

The measured zeta potential of natural magnetite, colloidal magnetite and colloidal magnetite interacted with oleate (oleate magnetite) as a function of $\mathrm{pH}$ using $\mathrm{NaNO}_{3}$ as electrolyte is shown in Fig. 11. It may be seen that PZC of natural magnetite is around $\mathrm{pH} 6.5$ while it is $\mathrm{pH} 6.8$ in the case of colloidal magnetite. PZC is shifted to $\mathrm{pH} 5.5$ in the case of oleate magnetite. Zeta potential of calcite and of calcite in the presence of various concentrations of oleate at assorted $\mathrm{pH}$ values under the constant ionic strength environment $\left(2 \times 10^{-3} \mathrm{M} \mathrm{NaNO}_{3}\right)$ is shown in Fig. 12. It can be seen that in case of calcite the zeta potential is negative over the entire $\mathrm{pH}$ range. It appears to have a minimum numerical negative value at $\mathrm{pH} 10.7$. The value varies from 17 to $67 \mathrm{mV}$. Considerable variation of the values of PZC on calcite reported by different investigators are noted. The PZC value range from $\mathrm{pH} 7.2$ to $\mathrm{pH} 10.5$ [17-19]. It can also be seen from Fig. 12 that the addition of sodium oleate results in further negative zeta potential values which are

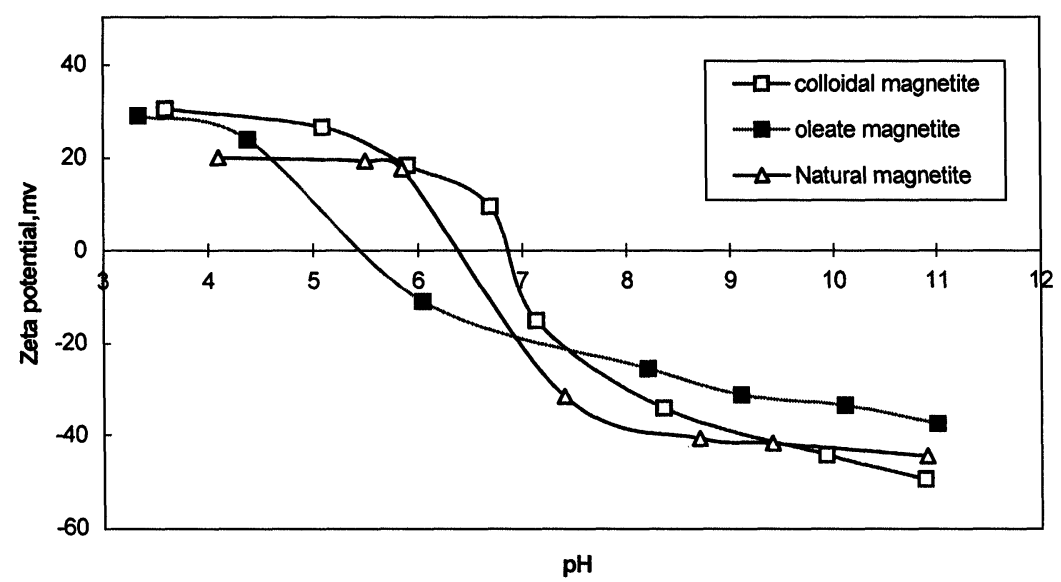

FIGURE 11 Zeta potential of colloidal magnetite, natural magnetite and oleate magnetite at different $\mathrm{pH}$. 


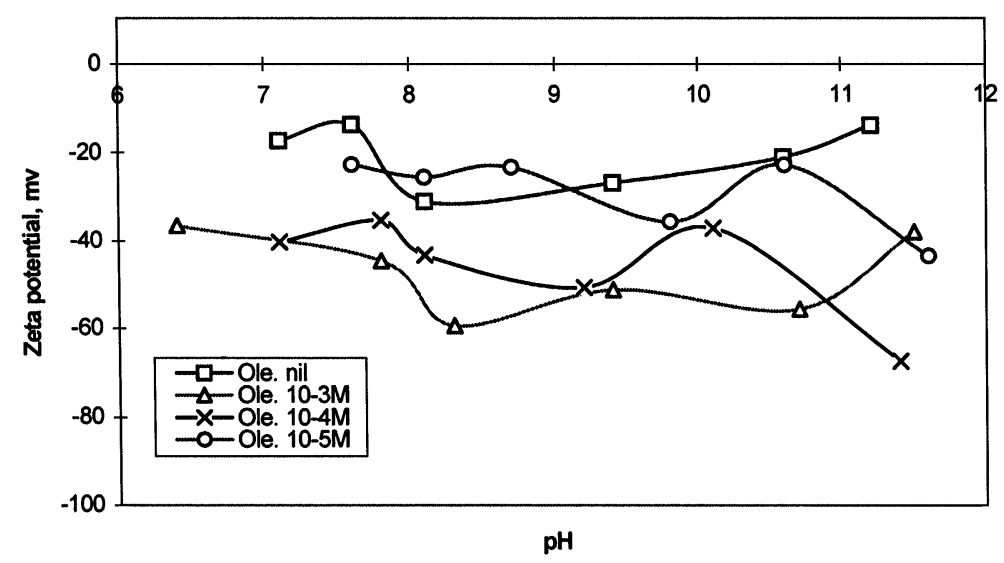

FIGURE 12 Zeta potential of calcite as a function of $\mathrm{pH}$ and the oleate concentration.

numerically larger. This negative value further increases with the increase in the oleate concentration $\left(1 \times 10^{-4}\right.$ to $\left.1 \times 10^{-3} \mathrm{M}\right)$.

As the point of zero charge of oleate magnetite is $\sim 5.5$ and calcite has negative zeta potential, the electrostatic attraction between calcite and oleate magnetite will only occur below this $\mathrm{pH}$. However as the calcite starts dissolving at acidic $\mathrm{pH}$, it is very difficult to carry out the coating and the separation tests. There may be some attraction between calcite and oleate magnetite as the minimum negative zeta potential of calcite is observed after $\mathrm{pH}$ 10.7. However it can be concluded that the role of electrostatic attraction between calcite and oleate magnetite particles appears to be negligible in the selective magnetite coating on calcite and strong chemical interaction is taking place as evidenced from IR data.

\section{Magnetic Susceptibility Measurements}

The results of magnetic susceptibility are given in Table IV. It can be seen that magnetic susceptibility increased from $5.9 \times 10^{-6}$ to $707.6 \times$ $10^{-6} \mathrm{emu} / \mathrm{g} / \mathrm{Oe}$. Magnetic susceptibility increases with the increase in the oleate magnetite. It has been observed that a small amount of magnetite is sufficient to increase the magnetic response of calcite. 
TABLE IV Magnetic susceptibility of calcite treated with different amount of oleate magnetite

\begin{tabular}{lc}
\hline $\begin{array}{l}\text { Amount of oleate magnetic } \\
\text { added }, \mathrm{mg} / \mathrm{g}\end{array}$ & $\begin{array}{c}\text { Magnetic susceptibility } \\
(\mathrm{emu} / \mathrm{g} / \mathrm{Oe}) \times 10^{-6}\end{array}$ \\
\hline 0 & 5.9 \\
7.5 & 225.8 \\
62.5 & 310.12 \\
87.5 & 427.80 \\
105 & 635.68 \\
150 & 707.6 \\
\hline
\end{tabular}

\section{CONCLUSIONS}

It has been demonstrated that it is technically possible to render selective coating on the calcite surface with natural or colloidal oleate magnetite. The technique has shown a potential use in a wide range of particle sizes from -30 to $150 \mu \mathrm{m}$. Separation is largely dependent on the surface charge. Calcite can be separated from associated gangue at $\mathrm{pH} \sim 11.0$ by using a small concentration of oleate magnetite and applying low to medium magnetic intensity.

\section{Acknowledgements}

Authors are grateful to Prof. H.S. Ray Director, RRL, Bhubaneswar for his permission to publish this paper. We are also thankful to Dr. D.K. Sengupta for useful discussions and to Dr. U.V. Mallavadhani for kindly recording the FTIR measurements.

\section{References}

[1] P. Parsonage, Selective magnetic coating for mineral separation, Trans. Inst. Min. Metal. Sect. C93 (1984), 37-44.

[2] W.A. Sauck, Magnetic susceptibility and magnetic content, Eco. Geol. 67 (1972), 383.

[3] R.H. Shubert, Magnetic separation of particulate mixture, US patent re 30 (1980), 360.

[4] P. Parsonage et al., Depressent function of calcite, apatite and dolomite. In Reagents in Mineral Industry (Jones M.J. and Obalattr Eds.) London; IMM (1984), pp. 33-40.

[5] A.F. Taggart, $A$ Hand Book of Mineral Dressing, Wiley, New York (1945).

[6] De Latour, IEEE Trans. Magn. 9(3) (1973), 314, 315.

[7] I. Iwasaki, Selective flocculation magnetic separation and flotation of ores. US patent, 4, 298, 169 (1981).

[8] J.K. Cook, Magnetic beneficiation of clays utilizing magnetic seeding and flotation, British patent, 2092026 (1981). 
[9] A.J. Nott and W.M. Price, Magnetic beneficiation of clays using magnetic particulate, US patent 4125460 (1981).

[10] M.H. Ahamad, Shaikh and S.G. Dixit, Role of magnetite and sodium oleate in the high gradient separation of calcite using magnetic coating of surface, J. Colloidal and Interface Science 155 (1993), 340-346.

[11] Qingxia Liu and F.J. Friedlaender, Fine particle processing by magnetic carrier, Min. Eng. 7 (1994), 449-463.

[12] C.H. Giles, T.N. Macewan, S.N. Nakhaw and D.J. Smith, Studies in adsorption. Part XI. A system of classification of solution adsorption isotherm and its use in diagnosis of adsorption mechanism and in measurement of specific surface areas of solids, Chem. Soc. (1960), 3973.

[13] V.C. Farmer, Infrared Spectra of Mineral, London, SW7,SHR. (1974).

[14] R.O. French et al., The quantitative application of infrared spectroscope to studies in surface chemistry, J. Phys. Chem. 58 (1954), 805-811.

[15] J.S. Hu, M. Mishra and J.D. Miller, Characterisation of adsorption oleate spectra at the fluorite surface by FTIR spectroscopy, Int. J. Miner. Process. 18 (1986), 73-84.

[16] K. Hanumanta Rao, B.H. Antti, J.M. Cases and E. Forssberg, Studies on the adsorption of oleate from aqueous solution onto apatite development in mineral processing, Proc. XVIth Int. Min. Proc. Cong. (K.S.E. Forssberg Ed.) Stockholm, Elsevier, Amsterdam (1988b), pp. 625-635.

[17] P. Somasundaran and G.E. Agar, The zero point charge of calcite, J. Colloid Interface Sc. 24 (1967), 433.

[18] M.C. Fuerstenau, G. Gutierrez and D.A. Elgillani, The influence of sodium silicate in non metallic flotation systems, Trans. AIME 241 (1968), 319.

[19] S.K. Mishra, The Electrokinetics of apatite and calcite in inorganic electrolyte environment, Int. J. Min. Process. 5 (1978), 69-83. 